\title{
PENGEMBANGAN MEDIA PEMBELAJARAN BERBASIS ANDROID DENGAN MENGGUNAKAN APLIKASI APPYPIE DI SMK BINA MANDIRI DEPOK
}

\author{
Irnin Agustina Dwi Astuti ${ }^{*}$, Dasmo ${ }^{1}$, Ria Asep Sumarni \\ ${ }^{1}$ Program Studi Pendidikan Fisika, Fakultas Matematika dan Ilmu Pengetahuan Alam, Universitas Indraprasta \\ PGRI, Jakarta, Indonesia \\ ${ }^{2}$ Program Studi Informatika, Fakultas Teknik dan Ilmu Komputer, Universitas Indraprasta PGRI, Jakarta, \\ Indonesia \\ *Penulis Korespodensi: irnin.agustina@gmail.com
}

\begin{abstract}
Abstrak
Tujuan kegiatan pengabdian masyarakat ini adalah untuk mengoptimalkan fungsi teknologi dan internet sebagai media pembelajaran berbasis android di SMK Bina Mandiri Depok. Media pembelajaran yang memanfaatkan teknologi telepon seluler disebut dengan mobile learning. Mobile learning merupakan salah satu alternatif pengembangan media pembelajaran. Kehadiran mobile learning ditujukan sebagai pelengkap pembelajaran serta memberikan kesempatan pada siswa untuk mempelajari materi yang kurang dikuasai di manapun dan kapanpun. Pelaksanaan kegiatan ini dalam tiga tahap yaitu tahap perencanaan, pelaksanaan, dan evaluasi. Tahap perencanaan yaitu menyiapkan bahan presentasi media pembelajaran android, modul pelatihan, serta sarana dan prasarana dalam menunjang pelatihan. Tahap pelaksanaan yaitu kegiatan pelatihan yang dilaksanakan pada tanggal 30-31 Mei 2016. Tahap evaluasi yaitu memberikan evaluasi terhadap hasil produk peserta pelatihan dalam bentuk aplikasi android. Metode yang digunakan dalam kegiatan pelatihan ini adalah dengan pelatihan dan pendampingan serta diskusi. Pelatihan dilakukan dengan cara memberikan informasi dalam membuat media pembelajaran berbasis android. Materi yang diberikan saat pelatihan memuat pembuatan, pengelolaan, pemanfaatan, dan penyebaran media pembelajaran dalam bentuk mobile learning. Hasil produk pelatihan ini dalam bentuk aplikasi media pembelajaran berbasis android yang dapat digunakan guru dalam menunjang kegiatan pembelajaran di kelas.
\end{abstract}

Kata kunci: Media Pembelajaran, Android, Appypie

\begin{abstract}
The purpose of the program devotion these communities is to optimize function of technology and internet as a medium learning based android in smk bina mandiri depok.Media learning used technology mobile phone called by mobile learning.Mobile learning is one of alternative development media learning.The presence of mobile learning intended as appendages learning and give opportunity to students to study material weaker anywhere and anytime). The implementation of this activity in three the phase planning, the implementation of the, and evaluation.The planning stages that is prepared the presentation material media learning android, module training, and infrastructures in supporting training.The implementation stage that is training activities that was held in date 30-31 may 2016.The evaluation namely providing evaluation of the results of products the participants in the form of the android application. Methods used in training activities are training and assistance and discussion .Training done by means of providing information in making media android based learning .The material is the load of training, management, the use of, and the spread of learning media in the mobile learning. The product this training in the media applications android based learning that can be used in the teacher support learning activities in class.
\end{abstract}

Keywords: Learning Media, Android, Appypie

\section{PENDAHULUAN}

Perkembangan ilmu pengetahuan dan teknologi yang sangat pesat saat ini menyebabkan hampir semua aktivitas manusia dapat dikendalikan oleh aplikasi Ilmu Pengetahuan dan Teknologi (IPTEK). Dengan semakin berkembangnya ilmu pengetahuan dan teknologi maka diperlukan suatu usaha yang dapat mempermudah mengetahui ilmu-ilmu tersebut (Wiyono dkk, 2012). Tingkat perkembangan perangkat smartphone yang semakin tinggi dan relatif semakin murah merupakan faktor pendukung pengguna smartphone meningkat. Pengguna smartphone Indonesia juga tumbuh pesat. 
Lembaga riset digital marketing Emarketer memperkirakan pada 2018 jumlah pengguna aktif smartphone di Indonesia akan mencapai lebih dari 100 juta orang. Dengan jumlah sebesar itu, Indonesia akan menjadi negara dengan pengguna aktif smartphone terbesar keempat di dunia setelah Cina, India, dan Amerika (Wahyudi, 2015).

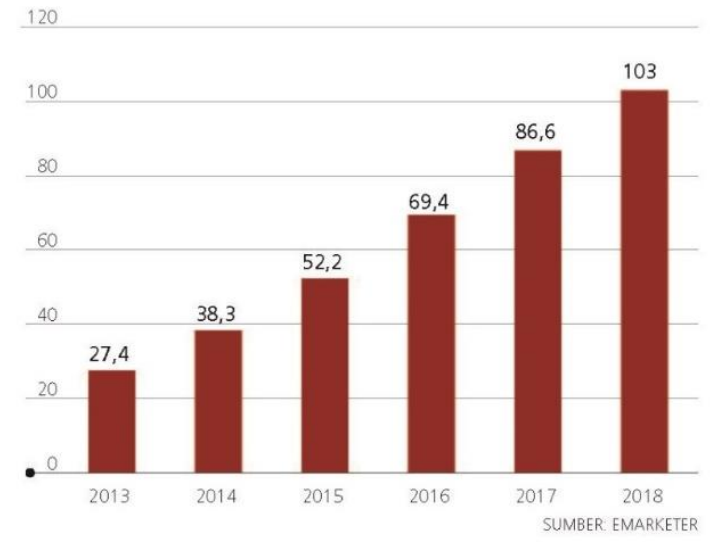

Gambar 1. Jumlah pengguna smartphone di Indonesia (juta)

Data tersebut menunjukkan bahwa tiap tahun pertumbuhan masyarakat indonesia tidak bisa lepas dari smartphone. Penggunanya merata semua kalangan masyarakat, baik dari anak-anak sampai orang dewasa sudah mempunyai smartphone dan mampu menggunakannya dengan baik. Hasil survey yang dilakukan Opera pada tahun 2013 di Indonesia menujukkan bahwa $10 \%$ pengguna android adalah umur 13-17 tahun. Hal ini membuktikan bahwa anak dengan usia tingkat SMP sampai SMA memiliki perhatian yang cukup besar dalam peng-gunaan smartphone.

Dunia pendidikan tidak terlepas dari proses pembelajaran yang meliputi guru, siswa, dan lingkungan pembelajaran yang saling mempengaruhi satu sama lain. Media merupakan salah satu faktor penunjang tercapainya tujuan pembelajaran (Astuti \& Bhakti, 2018). Hal ini berkaitan dengan penggunaan media yang tepat dan bervariasi dalam proses pembelajaran dapat meningkatkan motivasi belajar dan dapat mengurangi sikap pasif siswa.

Di SMK Bina Mandiri terlihat hampir sebagian siswa jarang berkunjung ke perpustakaan dikarenakan rendahnya minat siswa untuk membaca karena ketersediaan buku yang ada terlalu tebal sehingga menyebabkan siswa malas untuk membaca. Siswa pasti akan membutuhkan buku untuk menunjang materi dalam proses pembelajaran. Buku pelajaran yang ada saat ini perlu adanya inovasi supaya dapat mengikuti perkembangan zaman dan akan memudahkan siswanya untuk belajar, disesuaikan dengan kurikulum yang ada di sekolah. Buku paket pelajaran pada umumnya tebal dan berat sehingga membuat rendahnya minat siswa dalam membaca. Siswa lebih suka yang praktis dan instan. Bahan ajar pembelajaran yang sering digunakan di sekolah adalah power point, video pembelajaran, buku teks pelajaran, dan LKS (modul). Bahan ajar tersebut tidak bisa sewaktu-waktu digunakan oleh siswa dan dirasa kurang praktis.

Proses pembelajaran di SMK Bina Mandiri Depok masih satu arah, pembelajaran masih berpusat pada guru (teacher center) sehingga membuat siswa kurang termotivasi dalam belajar. Penggunaan media pembelajaran berbasis teknologi juga jarang dilakukan oleh guru, padahal sarana dan prasarana pendukung yang ada di sekolah memadai seperti wifi, LCD proyektor, dan laptop/komputer.

Media pembelajaran harus dikemas semenarik mungkin agar siswa bisa mudah memahami suatu materi. Salah satu media pembelajaran yang dapat dipakai untuk mengatasi masalah rendahnya minat siswa dalam membawa buku ke sekolah adalah pegembangan media berupa buku saku. Tetapi buku saku memiliki kelemahan yaitu kurang praktis jika dibawa kemana-mana. Oleh karena itu bahan ajar yang tepat yang bisa mendukung pembelajaran siswa sesuai perkembangan jaman adalah mobile learning berbasis android. Kurang variatifnya media yang dibagikan bukan semata-mata kesalahan guru, namun karena guru kurang mengoptimalkan perkembangan teknologi.

Perkembangan teknologi mobile saat ini begitu pesat, salah satu perangkat mobile yang saat ini sudah umum digunakan adalah telepon seluler. Hampir 90\% siswa di SMK Bina Mandiri Depok sudah mempunyai telepon seluler yang sudah android. Semakin banyaknya siswa yang memiliki dan menggunakan perangkat mobile maka semakin besar pula peluang penggunaan perangkat teknologi dalam dunia pendidikan.

Smartphone berpotensi untuk dapat digunakan sebagai salah satu media pembelajaran (Sulisworo, 2012). Hal ini menjadikan prospek penggunaan media pembelajaran berbasis smartphone menjadi sangat baik. Selain itu, penggunaan media belajar melalui smartphone juga dapat mengalihkan efek negatif dari penggunaan smartphone, seperti bermain game karena siswa dapat belajar melalui smartphone.

Media pembelajaran yang memanfaatkan teknologi telepon seluler disebut dengan mobile learning. Mobile learning merupakan salah satu alternatif pengembangan media pembelajaran. Mobile learning dapat dipandang sebagai suatu sistem yang dipandang dalam upaya meningkatkan kualitas pembelajaran dengan berupaya menembus keterbatasan ruang dan waktu (Darmawan, 2016). Kehadiran mobile learning ditujukan sebagai pelengkap pembelajaran serta memberikan kesempatan pada siswa untuk mempelajari materi yang kurang dikuasai di manapun dan kapanpun (Fatimah \& Mufti, 2014). Sekarang ini masih sedikit media pembelajaran yang memanfaatkan telepon seluler. Para siswa masih banyak yang menggunakan laptop atau bahkan masih ada yang menggunakan buku manual untuk menunjang 
pembelajaran di sekolah. Dengan menggunakan laptop sebagai media pembelajaran akan menyulitkan siswa membawa perangkat tersebut karena berat dan terkesan repot. Guru pun masih menggunakan metode konvensional dalam mengajar sehingga siswa merasa bosan ketika melakukan kegiatan pembelajaran. Melihat potensi ini, pengembangan media pembelajaran dengan memanfaatkan telepon seluler adalah dengan membuat mobile learning yang ditujukan untuk semua telepon seluler berplatform Android.

Android adalah sistem operasi berbasis Linux yang diperuntukkan untuk mobile device. Android merupakan sistem operasi yang paling diminati di masyarakat karena memiliki kelebihan seperti sifat open source yang memberikan kebebasan para pengembang untuk menciptakan aplikasi (Anggraeni \& Kustijono, 2013). Android secara sederhana bisa diartikan sebagai sebuah software yang digunakan pada perangkat mobile yang mencakup sistem operasi, middleware, dan aplikasi kunci yang dirilis oleh Google (Tim EMS, 2015).

Berdasarkan hasil penelitian yang dilakukan oleh Astra dkk (2015) menjelaskan bahwa aplikasi lab simulasi dapat digunakan sebagai media pembelajaran bagi siswa sekolah menengah atas karena rata-rata nilai kelayakan menunjukkan bahwa aplikasi tersebut layak dilakukan. Siswa dapat mempelajari konsep dengan baik. Selain itu siswa juga dapat mengevaluasi pengetahuan mereka dengan mengikuti bagian evaluasi.

Pembuatan media pembelajaran berbasis android yang mudah digunakan dan diaplikasikan yaitu dengan appypie. Appypie merupakan suatu website yang menyediakan template dalam pembuatan aplikasi android secara gratis dan berbayar. Appypie ini dapat mendukung proses pembuatan aplikasi pembelajaran berbasis Android, Mac OS, Windows Phone, Blackberry, dan HTML 5. Kelebihan appypie dibanding aplikasi yang lain yaitu tidak memerlukan koding (bahasa pemrograman) dalam membuat aplikasi, menyediakan template dalam pembuatan aplikasi android secara gratis dan ukuran file tidak terlalu besar sehingga mudah dioperasikan di smartphone. Sedangkan kelemahan dari pembuatan aplikasi pembelajaran dengan appypie adalah aplikasi yang sudah dibuat dengan appypie free ini hanya bisa diedit kembali satu kali dalam waktu 24 jam setelah selesai membuatnya, hanya bisa dikerjakan dengan koneksi internet (secara online) sehingga membutuhkan kuota internet yang cukup besar, dan muncul berbagai layanan iklan dalam aplikasi android jika sudah diinstal ke smartphone.

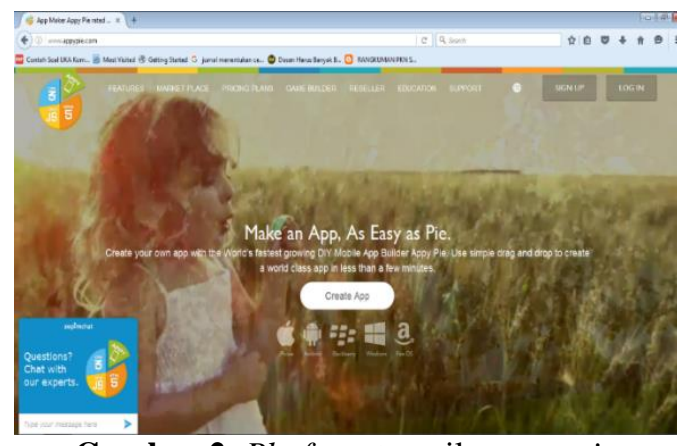

Gambar 2. Platform tampilan appypie

\section{BAHAN DAN METODE}

Kegiatan pengabdian masyarakat ini dilaksanakan di SMK Bina Mandiri Depok, yang beralamat di Jl. H. Sulaeman No. 10 Rt.01/07, Kelurahan Bedahan, Kecamatan Sawangan, Kota Depok, Jawa Barat. Kegiatan ini dilaksanakan pada bulan Mei - Juni 2016.

Metode yang digunakan untuk mencapai tujuan yang telah dirumuskan di atas adalah metode pelatihan dan pendampingan serta diskusi. Pelatihan dilakukan dengan cara memberikan informasi dalam membuat media pembelajaran berbasis android. Materi yang diberikan saat pelatihan memuat pembuatan, pengelolaan, pemanfaatan, dan penyebaran media pembelajaran dalam bentuk mobile learning.

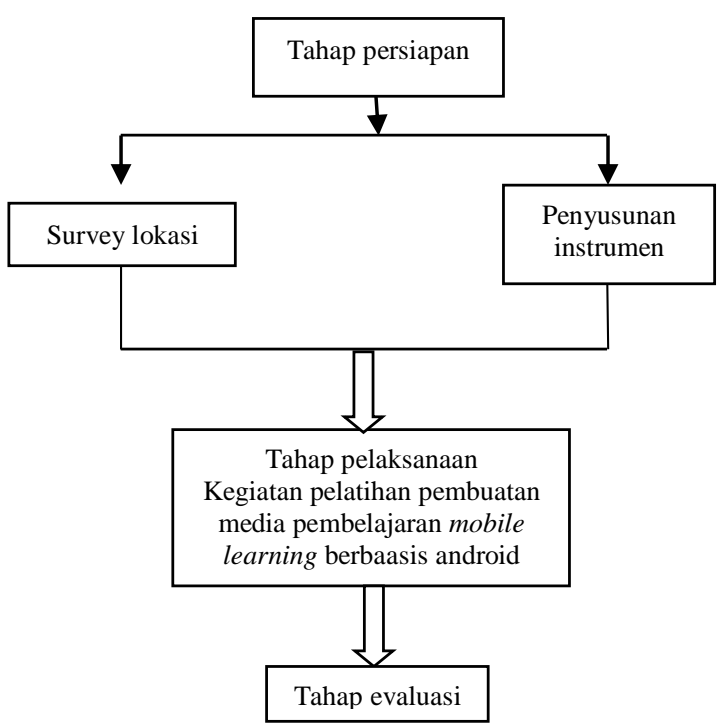

Gambar 3. Diagram alur kegiatan pengabdian masyarakat

Pelaksanaan kegiatan ini dilakukan dalam tiga tahap, yaitu tahap persiapan, pelaksanaan, dan evaluasi.

a) Tahap pertama adalah tahap persiapan. Dalam tahap ini tim melakukan survei pendahuluan untuk mengetahui kondisi target kegiatan dengan menganalisis kondisi tempat yang akan digunakan, kondisi peserta yang akan diberikan pelatihan, dan menyusun rancangan kegiatan yang akan dilakukan.

b) Tahap kedua yaitu tahap pelaksanaan. Tim melakukan pelatihan media pembelajaran mobile 
learning berbasis android yang ditujukan untu seluruh perangkat sekolah SMK Bina Mandiri Depok. Kegiatan pelatihan ini dilakukan agar guru bisa berinovasi dalam membuat media pembelajaran sehingga bisa digunakan dalam mendukung proses kegiatan belajar mengajar agar siswa tidak jenuh dan bosan saat pembelajaran.

c) Tahap ketiga adalah evaluasi. Evaluasi kegiatan ini dilakukan terhadap proses kegiatan. Evaluasi berkaitan selama kegiatan berlangsung dari tahap persiapan sampai tahap pelaksanaan, yang meliputi keadaan sekolah, kehadiran peserta pelatihan, antusias peserta saat mengikuti kegiatan, dan saran atau kritik terhadap kegiatan.

\section{HASIL DAN PEMBAHASAN}

Pelatihan pembuatan media pembelajaran berbasis android dengan aplikasi appypie banyak para guru yang belum begitu mengusai penggunaan android. Selama ini para guru belum pernah menggunakan media pembelajaran berbasis android, bahkan banyak beberapa yang baru pertama kali menggunakannya. Guru di sekolah ini masih menggunakan pembalajaran dengan buku dan papan tulis. Sarana dan prasarana yang tersedia di sekolah cukup memadai dan mendukung, banyak guru yang sudah menggunaakan laptop, $\mathrm{Hp}$ android dan ada sarana free wifi. Banyak siswa juga sudah menggunakan $\mathrm{Hp}$ android. Akan tetapi, sarana tersebut belum dimanfaatkan oleh guru secara maksimal.

Program pengabdian kepada masyarakat ini telah dilaksanakan pada tanggal 30 - 31 Mei 2016 di SMK Bina Mandiri Depok. Program ini bertujuan untuk melatih gruru dalam membuat media pembelajaran berbasis android dengan aplikasi appypie yang dapat digunakan guru dalam proses pembelajaran. Harapan dari kegiatan ini adalah guru bisa membuat media pembelajaran berbasis android yang dapat digunakan untuk memotivasi siswa dalam belajar agar siswa tidak jenuh dan bosan dalam Kegiatan Belajar Mengajar (KBM). Dalam pelaksanaannya kegiatan ini juga melibatkan tiga mahasiswa Program Studi Pendidikan Fisika Universitas Indraprasta PGRI.

Realisasi kegiatan ini dilakukan dalam tiga tahap, yakni tahap persiapan, pelaksanaan dan evaluasi. Tahap pertama adalah tahap persiapan. Pada tahap ini tim melakukan survei pendahuluan pada tanggal 24 Maret 2016 untuk mengetahui kondisi ditarget kegiatan dengan menganalisis kondisi tempat yang akan digunakan (laboratorium komputer), kondisi peserta yang akan diberikan perlakuan (guru dan karyawan sekolah) dan menyusun rancangan kegiatan yang akan dilakukan. Tahap persiapan selanjutnya tim menyiapkan bahan ajar, modul pelatihan media pembelajaran android, sarana dan prasarana untuk melengkapi kegiatan pelatihan seperti laptop, hp android serta modem untuk akses internet.
Tahap selanjutnya adalah tahap pelaksanaan. Pada tahap ini tim melakukan pelatihan guru dalam pembuatan bahan ajar dengan media pembelajaran berbasis android. Peserta pelatihan adalah semua guru dan karyawan di SMK Bina Mandiri sebanyak 18 orang.

Pada hari pertama pelatihan, para guru diberi pengetahuan dasar mengenai android. Pengetahuan dasar dalam pelatihan pembuatan media pembelajaran berbasis android adalah penguasaan penggunaan internet dan laptop. Pemahaman guru mengenai internet kurang, ini terbukti ketika guru membuat aplikasi android yang langkah awalnya harus pendaftaran terlebih dahulu lewat alamat email. Para guru masih banyak mengalami kesulitan dalam membuat email maupun menggunakan email, ada beberapa guru yang belum memiliki email, bahkan ada yang sudah memiliki email tetapi lupa paswordnya. Pelatihan ini mengharuskan para guru bisa menggunakan email, sehingga kami tim abdimas harus memberikan pelatihan dalam pembuatan dan penggunaan email terlebih dahulu sebelum melakukan pelatihan pembuatan media pembelajaran berbasis android.

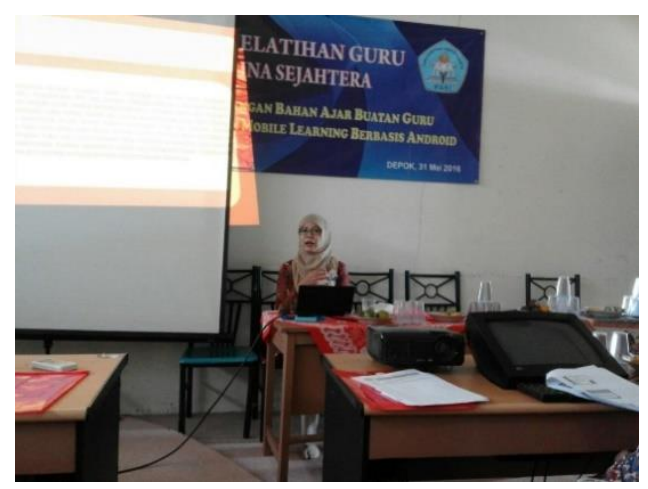

Gambar 4. Kegiatan sosialisasi.

Semua guru yang sudah memiliki email selanjutnya dibimbing untuk membuat media pembelajaran android melalui laptop. Ada guru yang sangat cepat dalam membuat media pembelajaran android, tetapi ada juga yang lamban dalam membuatnya. Para guru sangat semangat dalam pelatihan ini, sampai pada tahap terakhir pelatihan. Pada saat pelatihan guru-guru sangat antusias dan bersemangat dalam mengikuti rangkaian pelatihan yang dilakukan. Para guru juga melakukan diskusi dengan tim jika ada hal-hal yang masih bingung dalam pembuatan media pembelajaran berbasis android.

Pelaksanaan pelatihan waktu hari pertama hanya pelatihan dalam membuat aplikasi android dengan appypie yang isinya menambahkan materi atau teks dan menyisipkan gambar. Pada hari kedua pelatihan, para guru dilatih untuk menambah konten atau isi aplikasi android lebih kompleks lagi seperti menambahkan video, membuat link, membuat kuis interaktif dan 
menyimpannya sehingga hasil produk aplikasi android dapat di download dan di instal di hp android.

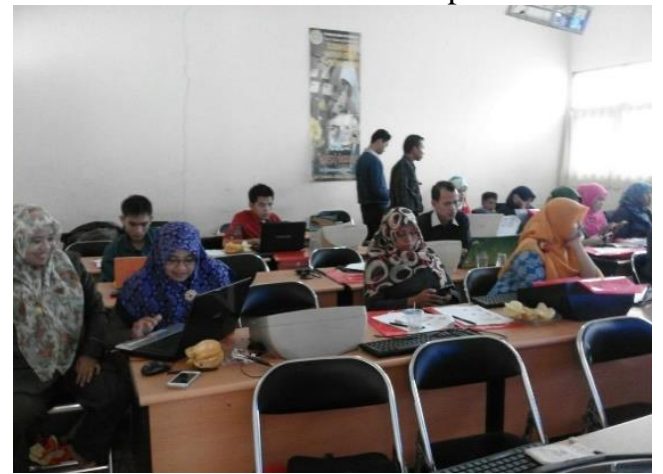

Gambar 5. Kegiatan pelatihan media pembelajaran berbasis android

Tahap terakhir adalah tahap evaluasi. Pada tahap ini, peserta pelatihan membuat suatu produk media pembelajaran berbasis android kemudian hasil produk tersebut dievaluasi oleh tim baik kekurangan dan kelebihan hasil produk media pembelajaran berbasis android.

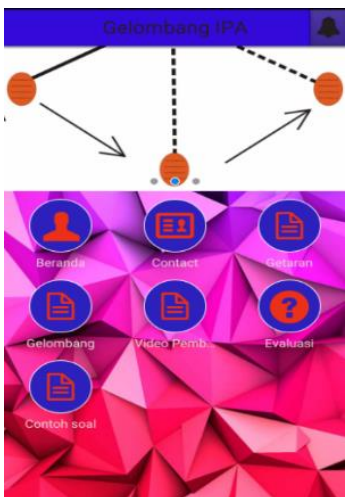

Gambar 6. Hasil produk media pembelajaran berbasis android guru IPA

Pada tahap evaluasi tim juga menganalisis kegiatan selama pelatihan. Secara keseluruhan tidak ada hambatan yang berarti, hanya saja pada saat pelaksanaan tidak selesai tepat waktu ini dikarenakan koneksi internet kurang stabil karena diakses banyak orang. Peserta pelatihan juga ada yang kurang paham mengenai penggunaan laptop dan internet sehingga trainer harus menjelaskan secara detail dan pelanpelan.Solusi yang diambil dalam mengatasi hambatan di atas adalah dengan menambah kuota internet untuk mengakses internet agar berjalan dengan baik. Solusi untuk mengatasi masalah kedua yaitu dengan memberikan tambahan pelatihan satu hari lagi untuk lebih memantapkan peserta pelatihan agar lebih paham dalam pembuatan media pembelajaran berbasis androiod.

Hasil produk media pembelajaran yang mereka buat bisa digunakan sebagai bahan ajar dikelas dalam pelaksanaan kegiatan belajar mengajar. Media pembelajaran ini diharapkan dapat dijadikan inovasi dalam pembelajaran yang dapat menarik minat siswa untuk lebih giat belajar. Dengan seperti ini kegiatan pelatihan ini sangat membantu guru dalam membuat suatu inovasi media pembelajaran yang baru dalam menunjang pembelajaran di kelas.

Sejalan dengan penelitian Astuti \& Bhakti (2018), media pembelajaran menjadi salah satu strategi baru dalam pembelajaran di kelas agar mendapatkan siswa mendapatkan pembelajaran yang bermakna, tidak membosankan, dan bersifat tidak abstrak. Penggunaan mobile learning terbukti mendorong motivasi dan dukungan siswa dalam kegiatan belajar mereka sendiri (Sulisworo dkk, 2016). Perkembangan teknologi multimedia menjanjikan potensi besar dalam mengubah cara siswa belajar. Multimedia juga memberikan peluang pendidikan dalam mengembangkan teknik pembelajaran (Taufiq dkk, 2017). Adanya media pembelajaran yang dibuat guru dapat membuat motivasi belajar siswa meningkat dan siswa tertarik pada pelajaran yang dibawakan guru. Menurut Bhakti \& Astuti (2018) tingkat skill atau kemampuan psikomotorik siswa akan meningkat jika pembelajaran yang diberikan guru diubah (tidak monoton) dan menggunakan media pembelajaran yang menarik.

\section{KESIMPULAN}

Secara keseluruhan kegiatan pengabdian mayarakat yang dilakukan di SMK Bina Mandiri Depok berjalan dengan baik. Guru-guru antusias mengikuti acara demi acara yang diberikan oleh tim. Dengan kegiatan pelatihan seperti ini ternyata guru memiliki minat yang tinggi dalam membuat bahan ajar media pembelajaran berbasis android, karena program seperti ini merupakan hal yang baru pertama dilakukan. Produk yang dihasilkan guru dalam bentuk aplikasi media pembelajaran berbasis android yang bisa digunakan guru dalam menunjang kegiatan pembelajaran di kelas. Luaran dari kegiatan pengabdian masyarakat ini dalam bentuk modul pembuatan media pembelajaran berbasis android yang dapat digunakan oleh pengajar baik guru, dosen, maupun masyarakat umum.

Berdasarkan hasil dan kesimpulan di atas, saran yang dapat diajukan antara lain 1) Guru lebih kreatif lagi dalam membuat inovasi media pembelajaran untuk mendukung kegiatan pembelajaran di kelas; 2) Sarana dan prasarana seperti koneksi inter yang ada di SMK Bina Mandiri Depok harus ditingkatkanlagi agar penggunaan koneksi internet dapat menjangkau dan memadai; 3) Media pembelajaran berbasis android dengan aplikasi appypie dapat dijadikan sebagai bahan ajar guru dalam kegiatan pembelajaran.

\section{UCAPAN TERIMA KASIH}

Penulis mengucapkan terimakasih kepada 1) Lembaga Penelitian dan Pengabdian Kepada Masyarakat (LPPM) Universitas Indraprasta PGRI yang telah memfasilitasi dan memberikan hibah DIPA untuk kegiatan program Abdimas, dan 2) Kepala Sekolah 
SMK Bina Mandiri Depok yang telah memberikan ijin kegiatan abdimas.

\section{DAFTAR PUSTAKA}

Anggraeni, R. D., \& Kustijono, R. (2013). Pengembangan media animasi fisika pada materi cahaya dengan aplikasi flash berbasis android. Jurnal Penelitian Fisika dan Aplikasinya (JPFA), 3(1), 11-18.

Astra, I. M., Nasbey, H., \& Nugraha, A. (2015). Development of an android application in the form of a simulation lab as learning media for senior high school students. Eurasia Journal of Mathematics, Science \& Technology Education, 11(5), 1081-1088.

Astuti, I. A. D., \& Bhakti, Y. B. (2018). Interactive Learning Multimedia Based Microsoft Excel on The Temperature and Heat. Unnes Science Education Journal, 7(1), 1-6.

Bhakti, Y. B., \& Astuti, I. A. D. (2018). The Influence Process of Science Skill and Motivation Learning with Creativity Learn. Journal of Education and Learning, 12(1), 30-35.

Dasmo, D., Astuti, I. A. D., \& Nurullaeli, N. (2017). Pengembangan Pocket Mobile Learning Berbasis Android. Jurnal Riset dan Kajian Pendidikan Fisika, 4(2), 71-77.

Darmawan, Deni. (2016). Mobile Learning Sebuah Aplikasi Teknologi Pembelajaran. Jakarta: Rajawali Pers.

Fatimah, S., \& Mufti, Y. (2014). Pengembangan Media Pembelajaran IPA-Fisika Smartphone Berbasis Android Sebagai Penguat Karakter Sains Siswa. Jurnal Kaunia, 10(1), 59-64.

Sulisworo, D. (2012). Enabling ICT and knowledge management to enhance competitiveness of higher education institutions. International journal of Education, 4(1), 112-121.

Sulisworo, D., Ishafit, I., \& Firdausy, K. (2016). The development of mobile learning application using jigsaw technique. International Journal of Interactive Mobile Technologies (iJIM), 10(3), 11-16.

Taufiq, M., Amalia, A. V., \& Parmin, P. (2017). The Development Of Science Mobile Learning With Conservation Vision Based On Android App Inventor 2. Unnes Science Education Journal, 6(1).

Tim EMS. (2015). Pemrograman Android dalam Sehari. Jakarta: Elex Media Komputindo.

Wahyudi, Ade. (2015). Indonesia, Raksasa Teknologi Digital Asia. http://katadata.co.id/opini/2015/09/29/indonesi a-raksasa-teknologi-digitalasia\#sthash.hmXDpXjY.dpbs. Diakses tanggal 20 Februari 2015.

Wiyono, K., Setiawan, A., \& Paulus, C. T. (2012). Model Multimedia Interaktif Berbasis Gaya Belajar Untuk Meningkatkan Penguasaan Konsep Pendahuluan Fisika Zat Padat. Jurnal Pendidikan Fisika Indonesia, 8(1), 74-82. 
